\title{
Effects of Switching from Insulin Glargine or Detemir to Insulin Degludec in Patients with Type 1 Diabetes Mellitus
}

\author{
Yoshiki Kusunoki $\cdot$ Tomoyuki Katsuno $\cdot$ Kana Miyakoshi $\cdot$ Takashi Ikawa $\cdot$ \\ Rie Nakae · Fumihiro Ochi · Masaru Tokuda - Takafumi Akagami $\cdot$ Kazuki Murai \\ Masayuki Miuchi · Tomoya Hamaguchi · Jun-ichiro Miyagawa • Mitsuyoshi Namba
}

To view enhanced content go to www.diabetestherapy-open.com

Received: October 1, 2013 / Published online: November 27, 2013

(C) The Author(s) 2013. This article is published with open access at Springerlink.com

\section{ABSTRACT}

Introduction: Insulin degludec is a new, ultralong-acting basal insulin. The aim of this study was to analyze the changes of basal insulin dose and blood glucose profile in basal-bolus therapy of type 1 diabetes mellitus (T1DM) at the switching of basal insulin from insulin glargine or detemir to insulin degludec.

Methods: Sixteen patients with T1DM were enrolled. The patients underwent continuous glucose monitoring before and after the

Y. Kusunoki $(\bowtie) \cdot$ T. Katsuno $\cdot$ K. Miyakoshi ·

T. Ikawa - R. Nakae $\cdot$ F. Ochi $\cdot$ M. Tokuda

T. Akagami · K. Murai · M. Miuchi · J. Miyagawa .

M. Namba

Division of Diabetes, Endocrinology, and

Metabolism, Department of Internal Medicine,

Hyogo College of Medicine, Nishinomiya,

Hyogo 663-8501, Japan

e-mail: ykusu@hyo-med.ac.jp

T. Hamaguchi

Innovative Diabetes Treatment, Hyogo College of

Medicine, Nishinomiya, Hyogo 663-8501, Japan

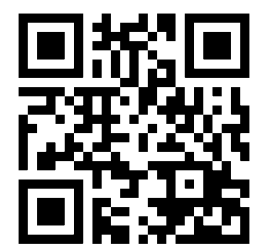

Enhanced content for this article is

available on the journal web site:

www.diabetestherapy-open.com switching of insulin glargine or detemir to degludec. Ten patients treated with insulin glargine or detemir twice daily, were switched to insulin degludec with $80-90 \%$ of the prior insulin dose. The remaining six patients treated with insulin glargine once daily, were switched to insulin degludec without down titration. The changes of daily insulin dose and glycated hemoglobin (HbA1c) were also examined for 12 weeks after switching to insulin degludec.

Results: In the patients switched from twicedaily basal insulin, no significant difference was found between before and after switching in the blood glucose profile. In the once-daily group, blood glucose levels showed a tendency to decrease after switching to the degludec treatment. During the study period, total daily insulin dose (TDD) and total daily basal insulin dose (TBD) decreased significantly in the twicedaily group, and TDD and TBD showed a tendency to decrease after switching to degludec in the once-daily group. In both groups, the changes of HbA1c were not significantly different.

Conclusion: It is possible to achieve similar glycemic control with once-daily injection and lower doses of insulin degludec in patients with 
T1DM who have been treated with insulin glargine or detemir.

Keywords: Basal-bolus insulin therapy; Continuous glucose monitoring; Hypoglycemia; Type 1 diabetes mellitus; Insulin degludec; Insulin glargine or detemir

\section{INTRODUCTION}

The cornerstone of the treatment of type 1 diabetes mellitus (T1DM), which is characterized by absolute deficiency of insulin secretion, is basal-bolus insulin therapy [1]. Physiological insulin secretion from the pancreas consists of two components, which are rapid release of insulin in response to food intake and basal secretion that plays a role in regulating hepatic glucose release while in fasting mode at night and between meals [2]. Patients with T1DM often require multiple daily injection (MDI) therapy using rapid-acting or ultra-rapid-acting insulin for additional supplementation and a basal dose of intermediate-acting or long-acting insulin [2]. In patients with T1DM, MDI therapy aimed at achieving strict glycemic control was shown to be effective for preventing the progression of microvascular disease by the Diabetes Control and Complications Trial [3].

When intermediate-acting insulin preparations are used as basal supplementation in MDI therapy, there can be problems with a spike of the blood insulin level and an insufficient duration of action, possibly causing nocturnal hypoglycemia and early morning blood glucose elevation [4].

Long-acting insulin preparations such as insulin glargine and insulin detemir were developed to overcome these demerits of intermediate-acting insulin preparations and achieve basal insulin levels that are more physiological [5-7]. There have been many reports so far that these long-acting insulin preparations decrease the risk of nocturnal hypoglycemia and also improve glycemic control compared with intermediate-acting insulin preparations [8-15].

Recently, insulin degludec (Novo Nordisk A/S. Bagsværd, Denmark) which is a soluble dihexamer preparation that forms stable and soluble multihexamers after subcutaneous injection has been developed [16]. The multihexamers remain at the injection site for some time and gradually dissolve to release monomers which means that insulin enters the blood in a slow and sustained manner [16]. The duration of action of degludec is further prolonged as the drug binds to albumin via fatty acid side chains both at the subcutaneous injection site and in the blood [16]. When 22 Japanese patients with T1DM received subcutaneous administration of insulin degludec at 0.4 units (U)/kg once daily for 6 days, the duration of action was reported to be over $26 \mathrm{~h}$ [17].

In a randomized, open-label, multicenter controlled study, 629 patients with T1DM underwent basal-bolus therapy for 52 weeks, in which insulin degludec or glargine was used as the basal insulin with additional insulin aspart [18]. Although glycemic control did not differ, nocturnal hypoglycemia was significantly less frequent in the degludec group [18]. In addition, when insulin degludec and detemir were compared in 456 patients with T1DM undergoing MDI therapy, noninferiority of glycemic control by degludec was demonstrated using glycated hemoglobin (HbA1c) as an indicator, while nocturnal hypoglycemia was significantly less frequent in the degludec group at 4 weeks after the initiation of treatment [17]. 
In the present study, we examined the efficacy of insulin degludec in comparison with insulin glargine or detemir for intensive insulin therapy in patients with T1DM.

\section{METHODS}

\section{Subjects}

The subjects of this study were patients with T1DM who had been treated with MDI therapy for over 12 months at the Division of Diabetes, Endocrinology, and Metabolism, Department of Internal Medicine, Hyogo College of Medicine (Hyogo, Japan). Patients were included if they were on treatment with insulin glargine or detemir as basal insulin therapy, had an HbA1c of $6.0 \%$ or greater and ad libitum serum C-peptide immunoreactivity (CPR) of less than $0.3 \mathrm{ng} / \mathrm{mL}$, and exhibited severe impairment of endogenous insulin secretion. They underwent continuous glucose monitoring (CGM) by wearing a portable monitor and were switched to insulin degludec. This study was approved by the Ethics Committee of Hyogo College of Medicine (No. 1425), and also has been registered in University hospitals Medical Information Network registry (No. 000010893). All procedures followed were in accordance with the ethical standards of the responsible committee on human experimentation (institutional and national) and with the Helsinki Declaration of 1975 , as revised in 2000 and 2008. Informed consent was obtained from all patients for being included in the study.

Exclusion criteria were: severe hepatic and/or renal impairment; severe infection, perioperative status, or severe trauma; pregnancy or a desire to become pregnant; ischemic heart disease (current treatment or past history); cancer; and other reasons leading the physician in charge to judge that the patient was unsuitable.

\section{Medications}

In patients who met the inclusion criteria and were confirmed to not fulfill any of the exclusion criteria, basal insulin was switched from insulin glargine or detemir to insulin degludec. Some patients were receiving insulin glargine or detemir twice daily (twice-daily group) while others were receiving basal insulin glargine once daily (once-daily group). According to the degludec dosage guide in Japan published by Novo Nordisk Pharma (Novo Nordisk Pharma, Ltd. Tokyo, Japan) [17], to switch to insulin degludec in the twice-daily group, patients were started on once-daily degludec at an initial dose that was $80-90 \%$ of the total glargine or detemir dose, and received a daily injection at a time decided according to their lifestyle. In the once-daily group, patients were started on once-daily degludec at the same dose as they had received during glargine treatment, and the timing of administration was also the same as for glargine or detemir. During the 12-week period, the basal insulin doses were adjusted by the attending physician as shown in Table 1.

For pre-prandial insulin supplementation, insulin aspart or insulin lispro had been used with the dose set by the carbohydrate counting method before the study and this was continued unchanged during the study period.

\section{Meals}

During the study period, hospitalized patients were given a diet with a total calorie intake of $25-30 \mathrm{kcal} / \mathrm{kg}$, which consisted of $55-60 \%$ carbohydrate, $15-20 \%$ protein, and $20-25 \%$ 
Table 1 Basal insulin adjustments during the 12-week study period

\begin{tabular}{ll}
\hline $\begin{array}{l}\text { Fasting plasma glucose } \\
\text { level }(\mathbf{m g} / \mathbf{d L})\end{array}$ & Dose adjustment \\
\hline$\leq 80$ & Decreased $10-20 \% /$ day \\
$81-150$ & No adjustment \\
$151-200$ & Increased $10 \% /$ day \\
& (or $1-2 \mathrm{U} /$ day) \\
$\geq 201$ & Increased $10-20 \% /$ day \\
& (or $2-3 \mathrm{U} /$ day) \\
\hline
\end{tabular}

$U$ units

fat. Outpatients were given a test diet $(1,500-1,600 \mathrm{kcal} /$ day; $55-60 \%$ carbohydrates, $15-20 \%$ protein, $20-25 \%$ fat) when CGM evaluation was performed on the day before and 3 days after switching treatment.

\section{Continuous Glucose Monitoring}

The study design is outlined in Fig. 1. For CGM, CGMS Gold $^{\circledR}$ (Medtronic Minimed, Northridge, USA) or $\mathrm{iPro}^{\mathrm{TM}} 2$ (Medtronic Minimed, Northridge, USA) monitors were used. Evaluation of the blood glucose profile was started while the patients were using glargine or detemir and was continued until the third day after switching to insulin degludec, when its blood level reached a steady state [17]. Then the CGM data obtained before switching and at the third day after switching were compared.

\section{Glycated Hemoglobin}

HbA1c was measured just before, 4 weeks after, and 12 weeks after switching to degludec.

\section{Statistical Analysis}

The Mann-Whitney $U$ test was used to compare background factors between the twice-daily group and the once-daily group. The Wilcoxon signed-ranks test was employed for comparison between immediately before and 3 days after switching to degludec, and it was used to compare the change of $\mathrm{HbA} 1 \mathrm{c}$ and insulin doses until 12 weeks after switching to degludec. StatView v5.0 software (SAS Institute Inc., Cary, NC, USA) was used for all analyses.

\section{RESULTS}

\section{Patient Characteristics}

All values are given as mean $\pm S D$ unless otherwise stated. A total of 16 patients with T1DM were included in the study. Twelve patients had a diagnosis by the detection of islet-associated autoantibodies, and four patients were diagnosed by their medical history. The ad libitum CPR levels of 11 patients were less than $0.03 \mathrm{ng} / \mathrm{mL}$ (not detectable), and the mean CPR levels of other 5 patients were $0.08 \pm 0.02 \mathrm{ng} / \mathrm{mL}$. Table 2 shows the characteristics of the patients in the once-daily and twice-daily groups. The twicedaily group included ten patients (3 male and 7 female). The once-daily group also included six patients ( 2 male and 4 female). The mean age of the twice-daily group was $56.0 \pm 17.9$ years, and that of the once-daily group was $69.3 \pm 17.6$ years, showing no significant difference. Mean HbA1c was $7.9 \pm 1.3 \%$ in the twice-daily group and $8.7 \pm 1.6 \%$ in the oncedaily group, while mean body mass index was $21.8 \pm 3.8 \mathrm{~kg} / \mathrm{m}^{2}$ versus $20.6 \pm 3.3 \mathrm{~kg} / \mathrm{m}^{2}$, with no significant differences between the two groups. Disease duration also did not differ significantly between the two groups, being $14.0 \pm 6.0$ years in the twice-daily group and $20.3 \pm 13.0$ years in the once-daily group, respectively. Total daily insulin dose (TDD) 


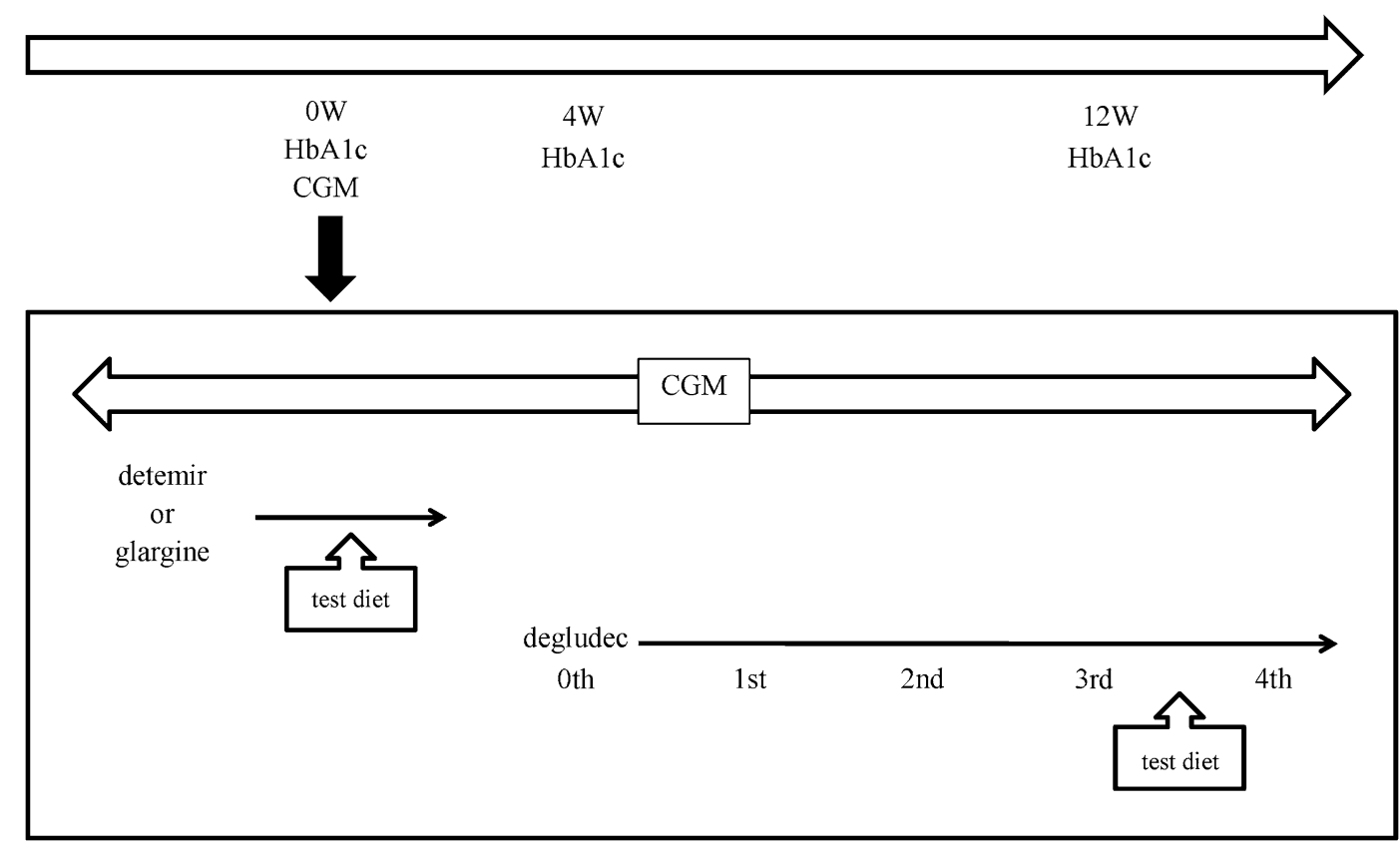

Fig. 1 Study design. $C G M$ continuous glucose monitoring, $H b A l c$ glycated hemoglobin, $W$ week

was $0.71 \pm 0.24 \mathrm{U} / \mathrm{kg}$ in the twice-daily group and $0.54 \pm 0.16 \mathrm{U} / \mathrm{kg}$ in the once-daily group, while total daily basal insulin dose (TBD) was $0.29 \pm 0.12 \mathrm{U} / \mathrm{kg}$ versus $0.21 \pm 0.08 \mathrm{U} / \mathrm{kg}$, and there were no significant differences between the two groups. The ratio of basal insulin to total daily insulin was $41.9 \pm 12.4 \%$ in the twice-daily group and $37.7 \pm 8.9 \%$ in the once-daily group, showing no significant difference. The basal insulin preparation was insulin glargine in six out of ten patients from the twice-daily group and all patients from the once-daily group. The insulin preparation used for pre-prandial bolus supplementation was either insulin aspart or insulin lispro, with eight patients in the twice-daily group and five patients in the once-daily group using insulin aspart.

\section{Insulin Dose}

In the twice-daily group, insulin degludec was initiated at a dose that was reduced to around
$80-90 \%$ of the prior insulin dose, so TBD showed a significant decrease from $0.29 \pm 0.12 \mathrm{U} / \mathrm{kg} \quad$ to $\quad 0.25 \pm 0.10 \mathrm{U} / \mathrm{kg}$

Table 2 Characteristics of enrolled patients

\begin{tabular}{llll}
\hline Variables & Twice daily & Once daily & $P$ value \\
\hline$n$ & 10 & 6 & - \\
Sex (male:female) & $3: 7$ & $2: 4$ & - \\
Age & $56.0 \pm 17.9$ & $69.3 \pm 17.6$ & n.s. \\
HbAlc (\%, NGSP) & $7.9 \pm 1.3$ & $8.7 \pm 1.6$ & n.s. \\
Body mass index & $21.8 \pm 3.8$ & $20.6 \pm 3.3$ & n.s. \\
$\quad\left(\mathrm{kg} / \mathrm{m}^{2}\right)$ & & & \\
Duration of & $14.0 \pm 6.0$ & $20.3 \pm 13.0$ & n.s. \\
diabetes (years) & & & \\
Glargine & 6 & 6 & - \\
Detemir & 4 & 0 & - \\
TDD/Wt (U/kg) & $0.71 \pm 0.24$ & $0.54 \pm 0.16$ & n.s. \\
TBD/Wt (U/kg) & $0.29 \pm 0.12$ & $0.21 \pm 0.08$ & n.s. \\
TBD/TDD (\%) & $41.9 \pm 12.4$ & $37.7 \pm 8.9$ & n.s. \\
\hline
\end{tabular}

n.s. not significant, $T B D$ total daily dose of basal insulin, $T D D$ total daily dose of insulin, $W t$ weight 
$(P=0.005)$ (Table 3A). In addition, the basal insulin to total daily insulin ratio was significantly decreased from $41.9 \pm 12.4 \%$ to $38.6 \pm 11.6 \% \quad(P=0.005) \quad$ (Table 3A). In the once-daily group, the insulin dose was the same before and after switching to degludec $(0.21 \pm 0.08 \mathrm{U} / \mathrm{kg})$ and the ratio of basal insulin to total daily insulin was also the same before and after switching $(37.7 \pm 8.9 \%$; Table 3B).

Furthermore, TDD (Fig. 2a) and TBD (Fig. 2b) after 12 weeks in the twice-daily group were significantly decreased. TDD and TBD after 12 weeks in the once-daily group had a tendency to decrease compared with before switching to degludec (TBD: $p=0.067$, TDD: $p=0.067$; Fig. 2).

\section{Comparison of Continuous Glucose Monitoring Findings}

\section{Mean Daily Blood Glucose Level}

In the twice-daily group, the mean blood glucose level was $154.8 \pm 34.0 \mathrm{mg} / \mathrm{dL}$ and $149.6 \pm 29.7 \mathrm{mg} / \mathrm{dL}$ before switching and 3 days after switching to insulin degludec, respectively, showing no significant change (Table 3A). In the once-daily group, the mean blood glucose level exhibited a tendency to decrease from $179.5 \pm 41.0 \mathrm{mg} / \mathrm{dL}$ before switching to $140.5 \pm 35.1 \mathrm{mg} / \mathrm{dL} 3$ days after switching to insulin degludec $(P=0.075$; Table 3B). The standard deviation showed no significant change in the twice-daily group $(58.5 \pm 23.6 \mathrm{mg} / \mathrm{dL}$ before switching and

Table 3 Daily blood glucose control and insulin dose in patients treated with twice daily of detemir or glargine (A) and once daily of glargine (B)

\begin{tabular}{llll}
\hline & Detemir or glargine & Degludec & P value \\
\hline (A) & & & \\
Mean (mg/dL) & $154.8 \pm 34.0$ & $149.6 \pm 29.7$ & n.s. \\
SD (mg/dL) & $58.5 \pm 23.6$ & $51.7 \pm 23.0$ & n.s. \\
Nocturnal hypoglycemia (0000-0600 hours, case) & 4 & 2 & - \\
TDD (U/kg) & $0.71 \pm 0.24$ & $0.69 \pm 0.23$ & 0.005 \\
TBD (U/kg) & $0.29 \pm 0.12$ & $0.25 \pm 0.10$ & 0.005 \\
TBD/TDD (\%) & $41.9 \pm 12.4$ & $38.6 \pm 11.6$ & 0.005 \\
\hline & Glargine & Degludec & $\boldsymbol{P}$ value \\
\hline (B) & & & \\
Mean (mg/dL) & $179.5 \pm 41.0$ & $140.5 \pm 35.1$ & 0.075 \\
SD (mg/dL) & $51.8 \pm 16.3$ & $50.2 \pm 19.2$ & n.s. \\
Nocturnal hypoglycemia (0000-0600 hours, case) & 0 & 2 & - \\
TDD (U/kg) & $0.54 \pm 0.16$ & $0.54 \pm 0.16$ & n.s. \\
TBD (U/kg) & $0.21 \pm 0.08$ & $0.21 \pm 0.08$ & n.s. \\
TBD/TDD (\%) & $37.7 \pm 8.9$ & $37.7 \pm 8.9$ & n.s. \\
\hline
\end{tabular}

n.s. not significant, $T B D$ total daily dose of basal insulin, $T D D$ total daily dose of insulin 

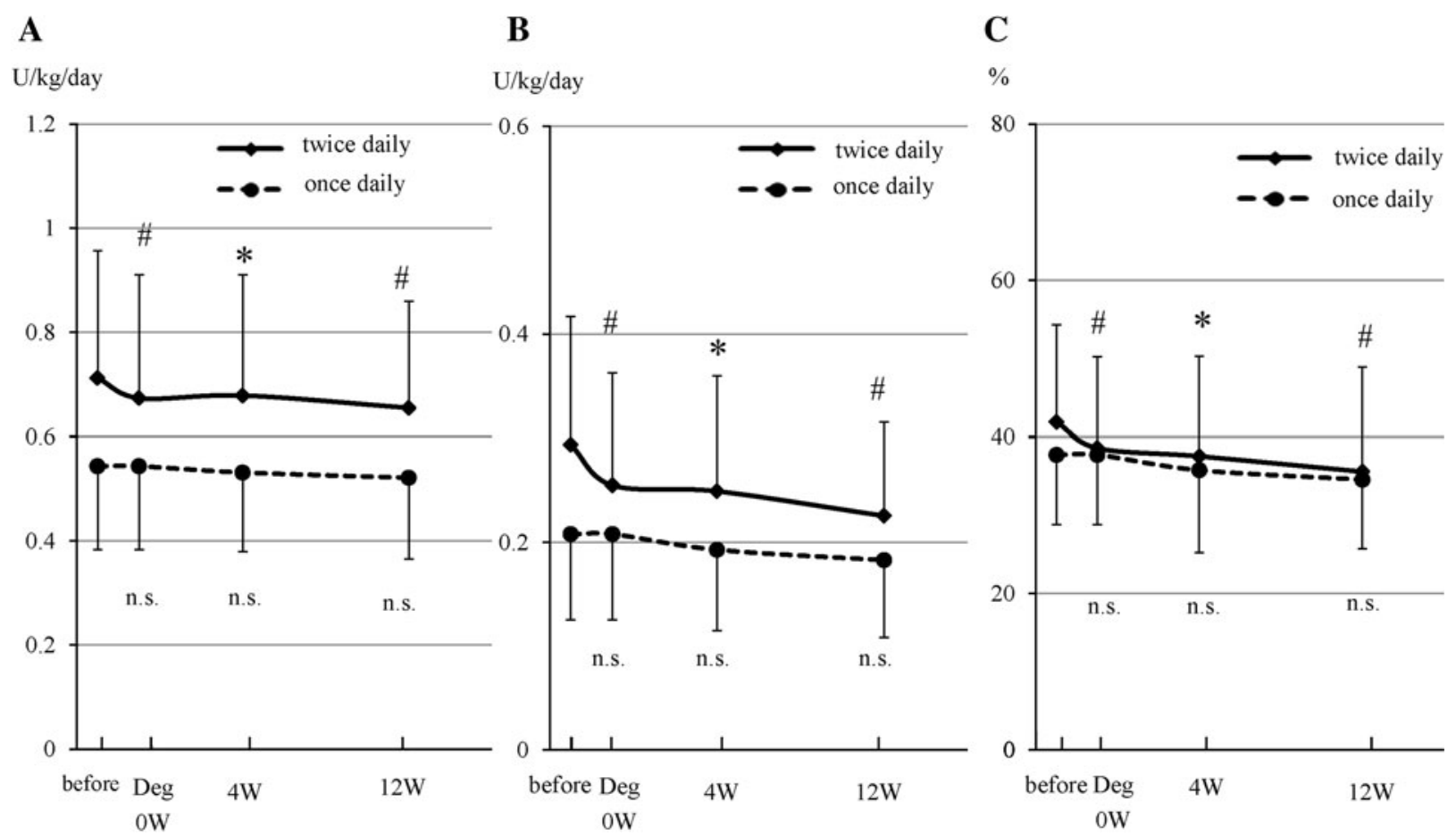

Fig. 2 Changes in TDD (a), TBD (b), and TBD/TDD (c) just before, 0, 4, and 12 weeks after switching to degludec. ${ }^{*} P<0.05$ and ${ }^{*} P<0.01$ versus baseline (glargine or detemir). Deg degludec, $n . s$. not significant

$51.7 \pm 23.0 \mathrm{mg} / \mathrm{dL}$ at 3 days after switching; Table 3A). There was also no significant change in the once-daily group $(51.8 \pm 16.3 \mathrm{mg} / \mathrm{dL}$ before switching and $50.2 \pm 19.2 \mathrm{mg} / \mathrm{dL}$ at 3 days after switching; Table 3B).

\section{Nocturnal Hypoglycemia}

Nocturnal hypoglycemia was defined as a blood glucose level of less than $70 \mathrm{mg} / \mathrm{dL}$ between 0000 and 0600 hours based on CGM data. In the twice-daily group, four patients developed nocturnal hypoglycemia before switching to insulin degludec and two patients had nocturnal hypoglycemia at 3 days after switching (Table 3A). In the once-daily group, none of the patients had nocturnal hypoglycemia before switching insulin degludec and two patients had nocturnal hypoglycemia at 3 days after switching (Table 3B).

\section{Nighttime and Daytime Blood Glucose Fluctuations}

When the nighttime period was defined as between 0000 and 0600 hours, the area under the blood glucose concentration versus time curve from 0000 to 0600 hours (AUC 0000-0600 hours) was $730.3 \pm 294.6 \mathrm{mg} \mathrm{h} / \mathrm{dL}$ before switching to insulin degludec and $933.6 \pm 390.0 \mathrm{mgh} / \mathrm{dL}$ at 3 days after switching in the twice-daily group, showing no significant change (Table 4). In the oncedaily group, the AUC 0000-0600 hours was from $925.3 \pm 297.2 \mathrm{mg} \mathrm{h} / \mathrm{dL}$ before switching to $907.9 \pm 573.6 \mathrm{mg} \mathrm{h} / \mathrm{dL}$ after switching, showing no significant change (Table 4).

Between 1600 and 1800 hours, since the influence of diet would be small and the effects of daytime basal insulin are easy to evaluate, CGM data which were mainly controlled with basal insulin showed that the area under the blood glucose concentration 
Table 4 Blood glucose area under the curve during 0000-0600 hours (A) and 1600-1800 hours (B) in patients treated with twice or once basal insulin

\begin{tabular}{|c|c|c|c|c|}
\hline & \multicolumn{2}{|l|}{ Twice daily } & \multicolumn{2}{|c|}{ Once daily } \\
\hline & $\begin{array}{l}\text { Detemir or } \\
\text { glargine }\end{array}$ & $\overline{\text { Degludec }}$ & Glargine & $\overline{\text { Degludec }}$ \\
\hline \multicolumn{5}{|c|}{ (A) AUC 0000-0600 hours (mg h/dL) } \\
\hline Mean & 730.3 & 933.6 & 925.3 & 907.9 \\
\hline SD & 294.6 & 390.0 & 297.2 & 573.6 \\
\hline$P$ value & n.s. & & n.s. & \\
\hline \multicolumn{5}{|c|}{ (B) AUC 1600-1800 hours ( $\mathrm{mg} \mathrm{h} / \mathrm{dL}$ ) } \\
\hline Mean & 523.3 & 425.1 & 547.0 & 346.8 \\
\hline SD & 251.3 & 118.3 & 241.5 & 115.3 \\
\hline$P$ value & n.s. & & 0.046 & \\
\hline
\end{tabular}

$A U C$ area under the curve, n.s. not significant

versus time curve from 1600 to 1800 hours (AUC 1600-1800 hours) was from $523.3 \pm 251.3 \mathrm{mgh} / \mathrm{dL}$ before switching to $425.1 \pm 118.3 \mathrm{mgh} / \mathrm{dL}$ at 3 days after switching to insulin degludec in the twicedaily group, showing no significant change. In the once-daily group, the AUC 1600-1800 hours decreased significantly from $547.0 \pm 241.5 \mathrm{mgh} / \mathrm{dL}$ before switching to $346.8 \pm 115.3 \mathrm{mg} \mathrm{h} / \mathrm{dL} \quad$ after switching degludec $(P=0.046)$.

\section{Glycated Hemoglobin}

There was no significant change in HbAlc after 12 weeks in the once-daily group (from $7.9 \pm 1.3 \%$ to $7.6 \pm 1.4 \%$ ), as well as in the twice-daily group (from $8.7 \pm 1.6 \%$ to $8.1 \pm 1.2 \%$; Fig. 3 ).

\section{DISCUSSION}

Previous studies compared insulin degludec with insulin glargine or detemir and showed

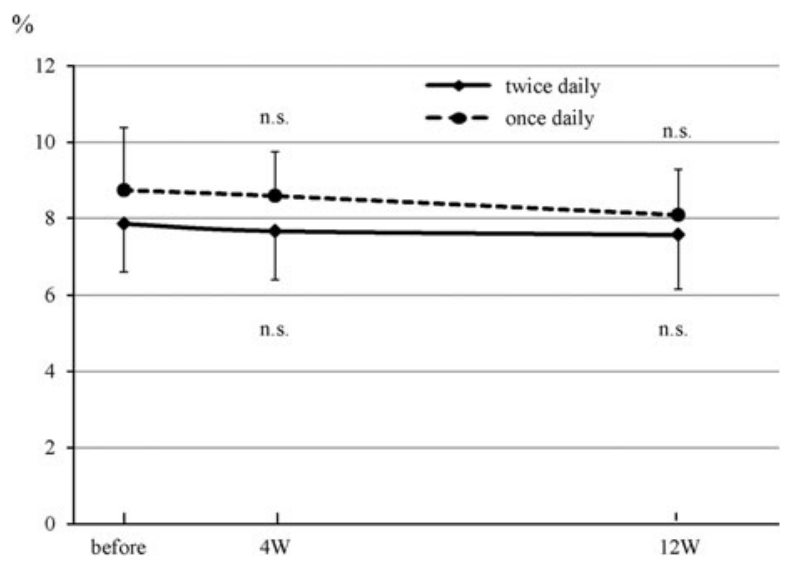

Fig. 3 Changes in glycated hemoglobin just before, 4 weeks after, and 12 weeks after switching to degludec versus baseline. n.s. not significant, $W$ week

that glycemic control was similar, but the frequency of nocturnal hypoglycemia was lower in the degludec group [18-23]. Heise et al. [24] showed degludec had a significantly more predictable glucose-lowering effect from day to day variability than glargine. However, no previous study assessed the changes of blood glucose or compared insulin doses just after switching to insulin degludec. The present study demonstrated the changes of glucose fluctuation and insulin dosage immediately after switching from insulin glargine or detemir to insulin degludec in patients with Japanese T1DM.

In this study, CGM did not reveal any significant changes of the AUC 0000-0600 hours, or the frequency of hypoglycemia after switching to insulin degludec. In the once-daily group, switching to insulin degludec was performed with the same dose and timing of insulin administration as before switching, but the blood glucose level showed a tendency to decrease within a few days of starting degludec. In the twice-daily group, treatment was initiated at a lower dose insulin degludec (reduced by 10-20\%) compared with that of insulin glargine or 
detemir, but CGM revealed no significant change of the mean blood glucose level.

It is possible that there was a residual effect of insulin glargine or detemir administered immediately before switching to degludec, since insulin glargine has a half-life of approximately $12 \mathrm{~h}$ and its duration of action is about $24 \mathrm{~h}$, while insulin detemir has a halflife of about $8-10 \mathrm{~h}$ and its duration of action is also about $24 \mathrm{~h}$. It has been reported that the duration of action of these insulins is prolonged in a dose-dependent manner [25]. However, CGM evaluation was performed 3 days after switching to insulin degludec in the present study and it is unlikely that the effect of glargine or detemir could persist until the third day. There is also a possibility that insulin degludec has a slightly stronger hypoglycemic effect compared with the same dose of glargine or detemir.

Heller et al. [18] has compared insulin degludec with insulin glargine for 52 weeks and showed that the mean values for TBD and TDD were significantly lower in the insulin degludec group relative to the insulin glargine group. Even in our study, 16 patients with type 1 diabetes mellitus, TBD and TDD were decreased after 12 weeks of treatment.

These results suggest that in patients who have already achieved good glycemic control, with lower fasting glucose levels and hypoglycemia easily, switching to insulin degludec would probably to be initiated at a lower insulin dose than that administered other basal insulin, in order to avoid an increase of hypoglycemia. Even when a patient is on twice daily with other basal insulin, decreasing the dose of insulin degludec is likely to be required. On the other hand, some studies reported that TDD and TBD were similar between insulin degludec and insulin glargine or detemir $[20,21]$.
Previous studies in patients with T1DM who were treated with insulin glargine or detemir showed that the ratio of basal insulin to total daily insulin was about 50-60\% [26, 27]. Another study in diabetic patients who treated with insulin degludec reported that the basal/bolus ratio was about 47:53 [18]. But several studies reported that the ratio of basal to total daily insulin was about $30-40 \%$ in Japanese patients with T1DM who were treated with insulin detemir, glargine or degludec [20, 28, 29]. The lower daily basal insulin dose in Japanese type 1 diabetes mellitus is probably explained by the generally higher carbohydrate content in Japan [30]. In this study, in the twice-daily group, the mean basal/bolus ratio was $42 / 58$ before switching and 36/64 after 12 weeks. In the once-daily group, the mean basal/bolus ratio was 38/62 before switching and 35/65 after 12 weeks. These findings do not differ greatly from previous studies in Japan [20, 28, 29, 31].

When once-daily injection of insulin glargine or detemir is used as basal insulin in insulin-depleted patients, they often show large diurnal variations of blood glucose due to the dawn phenomenon or Somogyi effect [32]. In these patients, it was reported that glycemic control can be improved by splitting the basal insulin dose and giving it twice daily [31, 33]. In the present study, 10 patients have been receiving twice-daily insulin glargine or detemir, so far. The present study demonstrates that changing from twice-daily administration of long-acting insulin to oncedaily insulin degludec can maintain the glycemic control with lower number of injection.

The present trial was subject to certain limitations. It was short duration and limited sample size. In addition, the present study was 
open-label in design and non-cross over trial. Therefore, larger sample size and double-blind crossover comparison may be necessary.

\section{CONCLUSION}

In patients with T1DM minimal endogenous insulin secretion, stable supplementation of basal insulin is essential to achieve good glycemic control, although some studies have been reported that conventional long-acting insulin preparations require twice-daily administration in many of these patients $[31,33]$. The results of the present study suggest that it is possible to achieve similar glycemic control by switching to once-daily insulin degludec in patients who are receiving conventional twice-daily long-acting insulin.

\section{ACKNOWLEDGMENTS}

Dr. Y. Kusunoki is the guarantor for this article, and takes responsibility for the integrity of the work as a whole. No funding or sponsorship was received for this study or publication of this article.

Conflict of interest. Y. Kusunoki, T. Katsuno, K. Miyakoshi, T. Ikawa, R. Nakae, F. Ochi, M. Tokuda, T. Akagami, K. Murai, M. Miuchi, T. Hamaguchi, J. Miyagawa, and M. Namba declare no conflict of interest.

Compliance with ethics guidelines. This study was approved by the Ethics Committee of Hyogo College of Medicine (No. 1425), and also has been registered in University hospitals Medical Information Network registry (No. 000010893). All procedures followed were in accordance with the ethical standards of the responsible committee on human experimentation (institutional and national) and with the Helsinki Declaration of 1975, as revised in 2000 and 2008. Informed consent was obtained from all patients for being included in the study.

Open Access. This article is distributed under the terms of the Creative Commons Attribution Noncommercial License which permits any noncommercial use, distribution, and reproduction in any medium, provided the original author(s) and the source are credited.

\section{REFERENCES}

1. American Diabetes Association. Standards of medical care in diabetes-2013. Diabetes Care. 2013;36(Suppl 1):S11-66.

2. Cheng AY, Zinman B. Principle of the insulin treatment. In: Kahn CR, Weir G, editors. Joslin's diabetes mellitus. 14th ed. Tokyo: Medical science international; 2007. p. 737-49 (in Japanese).

3. The Diabetes Control and Complications Trial Research Group. The effect of intensive treatment of diabetes on the development and progression of long-term complications in insulin-dependent diabetes mellitus. N Engl J Med. 1993;329:977-86.

4. Rosskamp RH, Park G. Long-acting insulin analogs. Diabetes Care. 1999;22(Suppl 2):B109-13.

5. Brunner GA, Sendhofer G, Wutte A, et al. Pharmacokinetic and pharmacodynamic properties of long-acting insulin analogue NN304 in comparison to NPH insulin in humans. Exp Clin Endocrinol Diabetes. 2000;108:100-5.

6. Heinemann L, Linkeschova R, Rave K, Hompesch B, Sedlak M, Heise T. Time-action profile of the longacting insulin analog insulin glargine (HOE901) in comparison with those of NPH insulin and placebo. Diabetes Care. 2000;23:644-9.

7. Gillies PS, Figgitt DP, Lamb HM. Insulin glargine. Drugs. 2000;59:253-60.

8. Ratner RE, Hirsch IB, Neifing JL, Garg SK, Mecca TE, Wilson CA. Less hypoglycemia with insulin glargine in intensive insulin therapy for type 1 diabetes. U.S. Study Group of Insulin Glargine in Type 1 Diabetes. Diabetes Care. 2000;23:639-43. 
9. Raskin P, Klaff L, Bergenstal R, Hallé JP, Donley D, Mecca T. A 16-week comparison of the novel insulin analog insulin glargine (HOE 901) and NPH human insulin used with insulin lispro in patients with type 1 diabetes. Diabetes Care. 2000;23:1666-71.

10. Schober E, Schoenle E, Van Dyk J, Wernicke-Panten $\mathrm{K}$, Pediatric Study Group of Insulin Glargine. Comparative trial between insulin glargine and $\mathrm{NPH}$ insulin in children and adolescents with type 1 diabetes mellitus. J Pediatr Endocrinol Metab. 2002;15:369-76.

11. Hermansen K, Madsbad S, Perrild H, Kristensen A, Axelsen M. Comparison of the soluble basal insulin analog insulin detemir with NPH insulin: a randomized open crossover trial in type 1 diabetic subjects on basal-bolus therapy. Diabetes Care. 2001;24:296-301.

12. De Leeuw I, Vague P, Selam JL, et al. Insulin detemir used in basal-bolus therapy in people with type 1 diabetes is associated with a lower risk of nocturnal hypoglycaemia and less weight gain over 12 months in comparison to NPH insulin. Diabetes Obes Metab. 2005;7:73-82.

13. Mathiesen ER, Hod M, Ivanisevic M, Detemir in Pregnancy Study Group, et al. Maternal efficacy and safety outcomes in a randomized, controlled trial comparing insulin detemir with NPH insulin in 310 pregnant women with type 1 diabetes. Diabetes Care. 2012;35:2012-7.

14. Frier BM, Russell-Jones D, Heise T. A comparison of insulin detemir and neutral protamine Hagedorn (isophane) insulin in the treatment of diabetes: a systematic review. Diabetes Obes Metab. 2013 (in press).

15. Albright ES, Desmond R, Bell DSH. Efficacy of conversion from bedtime NPH insulin injection to once- or twice-daily injections of insulin glargine in type 1 diabetic patients using basal/bolus therapy. Diabetes Care. 2004;27:632-3.

16. Jonassen I, Havelund S, Hoeg-Jensen T, Steensgaard DB, Wahlund PO, Ribel U. Design of the novel protraction mechanism of insulin degludec, an ultra-long-acting basal insulin. Pharm Res. 2012;29(8):2104-14.

17. Novo Nordisk Pharm Ltd. (Internal company data). http://www.novonordisk.co.jp (last accessed November 15, 2013).

18. Heller S, Buse J, Fisher M, et al. Insulin degludec, an ultra-longacting basal insulin, versus insulin glargine in basal-bolus treatment with mealtime insulin aspart in type 1 diabetes (BEGIN Basal-Bolus Type 1): a phase 3, randomised, open-label, treat-to- target non-inferiority trial. Lancet. 2012;379: 1489-97.

19. Zinman B, Philis-Tsimikas A, Cariou B, et al. Insulin degludec versus insulin glargine in insulin-naive patients with type 2 diabetes: a 1-year, randomized, treat-to-target trial (BEGIN Once Long). Diabetes Care. 2012;35:2464-71.

20. Iwamoto Y, Clauson P, Nishida T, Kaku K. Insulin degludec in Japanese patients with type 1 diabetes mellitus: a randomized controlled trial. J Diabetes Investig. 2013;4:62-8.

21. Hirsch IB, Bode B, Courreges JP, et al. Insulin degludec/insulin aspart administered once daily at any meal, with insulin aspart at other meals versus a standard basal-bolus regimen in patients with type 1 diabetes: a 26-week, phase 3, randomized, open-label, treat-to-target trial. Diabetes Care. 2012;35:2174-81.

22. Bode BW, Buse JB, Fisher M, et al. Insulin degludec improves glycaemic control with lower nocturnal hypoglycaemia risk than insulin glargine in basalbolus treatment with mealtime insulin aspart in Type 1 diabetes (BEGIN $\left({ }^{\circledR}\right)$ Basal-Bolus Type 1): 2 -year results of a randomized clinical trial. Diabet Med. 2013;30:1293-7.

23. Mathieu C, Hollander P, Miranda-Palma B, et al. Efficacy and safety of insulin degludec in a flexible dosing regimen vs insulin glargine in patients with type 1 diabetes (BEGIN: Flex T1): a 26-week randomized, treat-to-target trial with a 26-week extension. J Clin Endocrinol Metab. 2013;98: 1154-62.

24. Heise T, Tack CJ, Cuddihy $\mathrm{R}$, et al. A newgeneration ultra-long-acting basal insulin with a bolus boost compared with insulin glargine in insulin-naive people with type 2 diabetes: a randomized, controlled trial. Diabetes Care. 2011;34:669-74.

25. Klein O, Lynge J, Endahl L, Damholt B, Nosek L, Heise T. Albumin-bound basal insulin analogues (insulin detemir and NN344): comparable timeaction profiles but less variability than insulin glargine in type 2 diabetes. Diabetes Obes Metab. 2007;9:290-9.

26. Bartley PC, Bogoev M, Larsen J, Philotheou A. Longterm efficacy and safety of insulin detemir compared to Neutral Protamine Hagedorn insulin in patients with Type 1 diabetes using a treat-totarget basal-bolus regimen with insulin aspart at meals: a 2-year, randomized, controlled trial. Diabet Med. 2008;25:442-9.

27. Heller S, Koenen C, Bode B. Comparison of insulin detemir and insulin glargine in a basal-bolus 
regimen, with insulin aspart as the mealtime insulin, in patients with type 1 diabetes: a 52-week, multinational, randomized, open-label, parallel-group, treat-to-target noninferiority trial. Clin Ther. 2009;31:2086-97.

28. Kawamori R, Iwamoto $\mathrm{Y}$, Kadowaki T, Iwasaki M. Comparison of efficacy between insulin glargine and NPH human insulin in type 1 diabetes patients undergoing intensive insulin treatment. J Clin Ther Med. 2003;19(5):423-44 (in Japanese).

29. Kobayashi M, Iwamoto $\mathrm{Y}$, Kaku K, et al. 48-week randomized multicenter open-label parallel group phase 3 trial to compare insulin detemir and NPH insulin efficacy and safety in subjects with insulin requiring diabetes mellitus in a basal-bolus regimen. J Japan Diabetes Soc. 2007;50:649-63 (in Japanese).
30. Hashimoto T, Kawamura T, Kashihara Y, et al. Factors associated with basal insulin dose in Japanese children and young adult type 1 diabetics. J Diabetes Investig. 2012;3:276-82.

31. Katsuno T, Hamaguchi $\mathrm{T}$, Nagai E, et al. Influence of insulin glargine on basal insulin supplementation in Japanese Type 1 diabetic patients treated with basal-bolus injection therapy. J Japan Diabetes Soc. 2008;51:983-90 (in Japanese).

32. Bolli GB, Perriello G, Fanelli CG, De Feo P. Nocturnal blood glucose control in type I diabetes mellitus. Diabetes Care. 1993;16(Suppl 3):71-89.

33. Ashwell SG, Gebbie J, Home PD. Twice-daily compared with once-daily insulin glargine in people with Type 1 diabetes using meal-time insulin aspart. Diabetes Med. 2006;23:879-86. 